\title{
Upregulation of gamma-glutamyl-transpeptidase activity and uric acid level in mixed chemical exposure: implications for mutagenic and preneoplastic events
}

\author{
J. I. ANETOR ${ }^{1}$, D. UDAH ${ }^{1}$, T. S. AKINGBOLA ${ }^{2}$, G. O. ANETOR ${ }^{3}$, \\ O. O. BABALOLA ${ }^{1}$, O.G. IGHARO ${ }^{1,4^{*}}$, C.Z. UCHE $^{1}$ and F.A.A. ADENIYI ${ }^{1}$ \\ ${ }^{I}$ Department of Chemical Pathology, College of Medicine University of Ibadan, Ibadan, Nigeria. \\ ${ }^{2}$ Department of Haematology, College of Medicine, University of Ibadan, Ibadan, Nigeria. \\ ${ }^{3}$ Public Health Unit, School of Health Sciences, National Open University of Nigeria, Lagos, Nigeria. \\ ${ }^{4}$ Department of Medical Laboratory Science, School of Basic Medical Sciences, University of Benin, Benin \\ City, Nigeria. \\ *Corresponding author; E-mail: osaretin.igharo@uniben.edu; oigharo@yahoo.co.uk
}

\begin{abstract}
Mixed chemical toxicity including genotoxicity is currently a major concern in rapidly industrializing developing countries. Simple biomarkers remain a constraint. Gamma-glutamyl-transpeptidase (GGT), a precursor of glutathione, protects against chemical toxicity including genotoxic effects and may serve as a marker for pre-neoplastic lesion. The objective of the study was to determine a possible relationship between GGT, uric acid and the angiogenic agent copper $(\mathrm{Cu})$ in mixed chemical exposure. Sixty-six individuals occupationally exposed to mixed chemicals, mean age $34.4 \pm 1.27$ years, classified into 3 groups based on duration of exposure as follows: 1-10,11-20 and $>20$ years respectively, were enrolled into the study. Twentyseven, age- and sex-matched apparently healthy, occupationally unexposed individuals served as controls. The results showed that serum GGT was higher but not significantly different in exposed participants compared with controls; while its levels varied significantly with duration of exposure across the exposure groups. Like GGT, uric acid was significantly higher in the exposed than in controls and both significantly positively correlated with duration of exposure. Copper was higher in the exposed than the unexposed controls and correlated positively with GGT but not significantly. This observed up-regulation of GGT and its positive correlation with uric acid levels may be a protective response against oxidative stress arising from or related to the depletion of thiol group; thus enhancing maintenance of GSH levels; and may serve as an inexpensive early biomarker of mutagenicity in mixed chemical exposure.
\end{abstract}

(C) 2016 International Formulae Group. All rights reserved.

Keywords: Gamma-glutamyl-transpeptidase, uric acid, mixed chemical exposure, genotoxicity, mutagenicity.

\section{INTRODUCTION}

Increasing exposure to a mixture of chemicals as a result of rapid industrialization is currently of great public health concern in developing countries (Yáñez et al., 2002), where exposure to hazardous chemicals considerably exceeds established limits in the industrialized nations. Even in the developed countries with increasing development and industrialization, these environmental problems have escalated faster than their ability to collect sufficient data that would 
have enhanced agreement among scientists on the magnitude of the problems. Also in developing countries, some significant environmental pollutions have been linked with human activities such as smoking (Gashaw et al., 2016). Additionally, chemicals previously banned in the developed countries are now produced in significant amounts in these countries (Yáñez et al., 2002). These countries also lack the appropriate technology to monitor exposure rates. Cancer, in general, results from interactions between environmental exposures and genetics, culminating in genomic instability. Recent cancer statistics from the World Health Organization (WHO) Reports show that the incidence of all cancers is increasing globally but particularly in developing countries; more than $60 \%$ of world's total new annual cases occur in Africa, Asia and Central and South America (de Martel et al., 2012).

Furthermore, while the number of occupational cancers has decreased, in most industrialized countries the reverse is the case in developing countries partly owing to the ongoing transfer of hazardous industries to developing countries (de Martel et al., 2012); thus the need for sensitive but affordable indicators of risk (risk assessment).

In recent years, our knowledge of the physiological function of gammaglutamyltranspeptidase (GGT) has expanded and several important epidemiological associations have been reported (Whitfield, 2007). In particularly, association has been established between environmental pollutants and GGT levels (Lee and Jacobs, 2006). Gamma-glutamyl transpetidase, like glutathione-S-transferase placental form (GST-P) participates in generating glutathione (GSH) to protect against chemical toxicity including mutagenic and genotoxic effects and may serve as a marker of pre-neoplastic lesion (Satoh and Hatayama, 2002). Additionally, uric acid and GGT activity have been associated with left ventricular remodeling indices in patients with chronic heart failure (Radovanovic et al., 2014). Also, Lee et al. (2004) and Rahman and MacNee (2000) documented the role of GGT in the oxidative stress regulation of glutathione in lung inflammation. The possible relationship of GGT to the potent metabolic antioxidant, uric acid and the angiogenic agent copper $(\mathrm{Cu})$ has not been examined, particularly in a typical rapidly industrializing developing country like Nigeria.

The objective of this study was therefore to determine a possible relationship between GGT, uric acid and the angiogenic agent copper in Nigerians occupationally exposed to mixed chemicals.

\section{MATERIALS AND METHODS}

\section{Study area}

The study was carried out in Ibadan metropolis (Figure 1). Exposed participants were recruited from selected mechanic workshops in the metropolis while the control participants were recruited from the University of Ibadan and the University College Hospital environment.

\section{Study population}

Sixty-six (66) male employees, mean age $34.6 \pm 1.27$ (range 21-70) years were selected for this investigation. They were classified into 3 groups based on duration of exposure to chemical mixtures as follows: group I (1-10 years exposure duration); group II (11-20 years exposure duration) and group III ( $>20$ years exposure duration). The chemical workers comprised of battery workers, auto mechanics, auto painters, welders, electricians, vulcanizers, petrolcarbon workers and other organic solvent handlers/dispensers. The mean duration of persistent exposure was $14.85 \pm$ 1.09 (range 2-46) years. Twenty-seven (27) apparently healthy male participants and occupationally unexposed participants matched for age and body mass index served as unexposed participants. Consumption of alcohol was similar in both groups.

These unexposed participants had no history of hobby / occupational exposure to chemicals. Informed consent was obtained from all 93 participants after educating them on the nature, relevance and benefit of the study. Body mass index (BMI) was computed 
for all participants from their weights and heights using standard formula.

About $10 \mathrm{ml}$ of venous blood was collected from the antecubital fosa vein of each participant with pyrogen free syringes and needles. Blood samples were carefully dispensed in eparinized containers stoppered and mixed gently by inverting several times. The samples were centrifuged at $3000 \mathrm{rpm}$ for 5 minutes. Separated plasma samples were stored frozen at $-20{ }^{\circ} \mathrm{C}$ until analyzed.

\section{Biochemical assays}

Standard liver function biochemical panel comprising of serum bilirubin level, alkaline phosphatase (ALP), alanine aminotransferase (ALT), aspartate aminotransferase (AST) activities as well as serum total protein and albumin levels, was used to exclude biochemical evidence of liver pathology in both the study and control participants. The ALP, ALT and AST activities were determined according to the methods described by Bergmeyer et al. (1986b) and Tietz and Shuey (1986) respectively. Serum GGT and uric acid levels were determined by standard spectrophotometric methods as previously described by Committee of Enzymes of the
Scandinavian Society for Clinical Chemistry and Clinical Physiology (1976), and Town et al. (1985) respectively. Serum copper was determined by atomic absorption spectrophotometry (AAS) as described by Osheim (1983). Serum protein and bilirubin levels were determined by standard biochemical techniques as described by Doumas et al. (1981), and Jendrassik and Groff (1938) respectively.

\section{Statistics}

Statistical analyses were conducted using a number of statistical techniques. The two-tailed independent Student's t-test of significance, at $95 \%$ confidence limit $(p<0.05)$, was adopted in comparing changes between exposed and unexposed populations. The one-way analysis of variance (ANOVA) was used to investigate variations in the values of all parameters measured among the groups. A post-hoc test was done using the least significance difference (LSD) method for significant ANOVA results. Correlation studies were performed using the Pearson's Product Moment coefficient. All values were reported as the mean \pm standard error of mean (SEM).

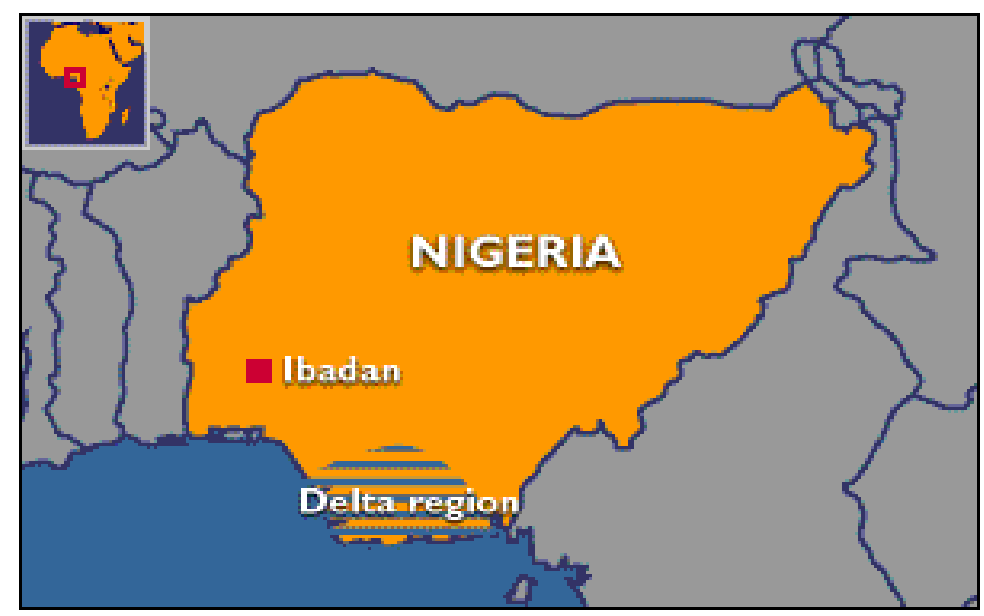

Figure 1: Nigeria map shows the location of Ibadan. 


\section{RESULTS}

The results obtained from this study are shown in the tables below. Table 1 shows Age, BMI, GGT, uric acid, copper and total Globulin levels in exposed and unexposed participants. Uric acid level was higher and significantly different in the exposed group $(328.44 \pm 6.55 \mu \mathrm{mol} / \mathrm{L})$ compared with the unexposed group $(304.46 \pm 9.52 \mu \mathrm{mol} / \mathrm{L})$. Age, BMI and levels of GGT, $\mathrm{Cu}$, total bilirubin, albumin and globulin did not vary significantly between the two groups of participants $(p>0.05)$. Duration of exposure, age, height and BMI are shown in Table 2; with the exception of height, it was observed that age, weight and BMI varied with the duration of exposure classified into groups IIII. Plasma levels of GGT, $\mathrm{Cu}$, Uric acid, total bilirubin and globulin are shown in Table 3; Uric acid and GGT levels were significantly higher in participants with the longest duration of exposure (i.e. $>20$ years). The levels of GGT and uric acid in group II (11-20 years exposure duration) were significantly raised compared with group I with less than 10 years exposure duration. However, bilirubin and $\mathrm{Cu}$ levels did not vary with exposure duration.

Correlation of exposure duration with $\mathrm{GGT}, \mathrm{Cu}$, Uric acid, globulin and conjugated bilirubin demonstrated a significant positive correlation between GGT and duration of exposure $(\mathrm{r}=0.30, \mathrm{p}<0.05)$; and between uric acid and exposure duration $(\mathrm{r}=0.34, \mathrm{p}<0.05)$ (Table 4). Other correlations and associations were not significant. Correlation evaluation among GGT, bilirubin, globulin, uric acid and $\mathrm{Cu}$ showed that GGT correlated positively and significantly with uric acid $(\mathrm{r}=0.27 ; \mathrm{p}<0.05)$ (Table 5). Other correlations were again not significant.

Table 1: Age, BMI, GGT, Uric acid, Copper and total Globulin in exposed and unexposed subjects.

\begin{tabular}{|c|c|c|c|c|}
\hline Variables & $\begin{array}{l}\text { Exposed } \\
\text { participants } \\
(n=66)\end{array}$ & $\begin{array}{l}\text { Unexposed } \\
\text { participants } \\
(n=27)\end{array}$ & t-value & P-value \\
\hline Age (Years) & $34.64 \pm 1.27$ & $32.15 \pm 1.58$ & 1.11 & $>0.05$ \\
\hline BMI $\mathrm{Kg} / \mathrm{m}^{2}$ ) & $23.03 \pm 0.30$ & $22.73 \pm 0.52$ & 0.52 & $>0.05$ \\
\hline GGT (U/L) & $34.47 \pm 5.05$ & $28.52 \pm 2.02$ & 1.76 & $>0.05$ \\
\hline Copper $\mu \mathrm{mol} / \mathrm{L}$ ) & $15.50 \pm 0.40$ & $14.3 \pm 0.40$ & 1.76 & $>0.05$ \\
\hline $\begin{array}{l}\text { Uric acid } \\
(\mu \mathrm{mol} / \mathrm{L})\end{array}$ & $328.44 \pm 6.55$ & $304.46 \pm 9.52$ & 1.99 & $<0.05^{*}$ \\
\hline $\begin{array}{l}\text { T.Bilirubin } \\
(\mu \mathrm{mol} / \mathrm{L})\end{array}$ & $10.41 \pm 0.60$ & $11.03 \pm 1.01$ & 0.53 & $>0.05$ \\
\hline Albumin $(\mathrm{g} / \mathrm{L})$ & $45.68 \pm 0.39$ & $46.49 \pm 0.067$ & 1.04 & $>0.05$ \\
\hline Globulin $((\mathrm{g} / \mathrm{L})$ & $44.07 \pm 0.73$ & $46.26 \pm 0.067$ & 1.76 & $>0.05$ \\
\hline
\end{tabular}


Table 2: Age, height, BMI and exposure duration in all categories of exposure and in controls.

\begin{tabular}{|c|c|c|c|c|c|c|}
\hline Groups & $\begin{array}{l}1 \\
n=25\end{array}$ & $\begin{array}{l}\text { II } \\
n=24\end{array}$ & $\begin{array}{l}\text { III } \\
n=17\end{array}$ & $\begin{array}{l}\text { Control } \\
(n=-27)\end{array}$ & $\mathbf{F}$ & $\mathbf{P}$ \\
\hline Age (Years) & $26.88 \pm 0.98$ & $34.88 \pm 1.40$ & $45.71 \pm 2.51$ & $32.15 \pm 1.50$ & 21.45 & $<0.01 * *$ \\
\hline Weight $(\mathrm{kg})$ & $65.20 \pm 1.02$ & $64.21 \pm 1.51$ & $74.53 \pm 2.33$ & $67.30 \pm 1.61$ & 6.77 & $<0.01 * *$ \\
\hline Height (m) & $1.71 \pm 0.01$ & $1.70 \pm 0.01$ & $1.71 \pm 0.02$ & $1.72 \pm 0.01$ & 0.35 & $>0.05$ \\
\hline BMI $\left(\mathrm{kg} / \mathrm{m}^{2}\right)$ & $22.21 \pm 0.28$ & $22.11 \pm 10.47$ & $25.52 \pm 057$ & $22.72 \pm 0.49$ & 9.64 & $<0.01 * *$ \\
\hline $\begin{array}{l}\text { Mean duration } \\
\text { of exposure } \\
\text { (years) }\end{array}$ & $6.60 \pm 0.42$ & $15.00 \pm 0.70$ & $26.76 \pm 1.51$ & & 247.65 & $<0.001 * *$ \\
\hline
\end{tabular}

** Statistically significant at the $\mathrm{P}<0.01$ level.

Group I: duration 1-10 years; Group II: exposure duration of 11-20 years; Group III: exposure duration -20 years.

Table 3: Plasma levels of GGT, Copper, uric acid, Bilirubin and Globulin.

\begin{tabular}{lllllll}
\hline Group & $\begin{array}{l}\text { I } \\
(\mathbf{n}=\mathbf{2 5})\end{array}$ & $\begin{array}{l}\text { II } \\
(\mathbf{n}=\mathbf{2 4})\end{array}$ & $\begin{array}{l}\text { III } \\
(\mathbf{n}=\mathbf{1 7})\end{array}$ & $\begin{array}{l}\text { Controls } \\
(\mathbf{n}=\mathbf{2 7})\end{array}$ & $\mathbf{F}$ & $\mathbf{P}$ \\
\hline GGT (U/L) & $20.57^{\mathrm{C}} \pm 1.54$ & $34.46^{\mathrm{B}} \pm 3.05$ & $54.92^{\mathrm{A}} \pm 18.30$ & $28.52 \pm 1.91$ & 3.76 & $<0.05$ \\
$\begin{array}{l}\text { Copper } \\
(\mu \mathrm{mol} / \mathrm{L})\end{array}$ & $15.10 \pm 0.50$ & $15.40 \pm 0.80$ & $17.10 \pm 2.70$ & $14.30 \pm 0.40$ & 0.932 & $>0.05$ \\
$\begin{array}{l}\text { Uric acid } \\
(\mu \mathrm{mol} / \mathrm{L})\end{array}$ & $311.78^{\mathrm{C}} \pm 7.74$ & $326.66^{\mathrm{C}} \pm 11.34$ & $355.22^{\mathrm{C}} \pm 13.69$ & & 3.78 & $<0.03$ \\
$\begin{array}{l}\text { Conj. } \\
\text { Bilirubin } \\
(\mu \text { mol/L) }\end{array}$ & $2.30 \pm 030.17$ & $2.28 \pm 30.24$ & $2.76 \pm 030.36$ & $2.10 \pm 30.24$ & 1.13 & $>0.05$ \\
\hline $\begin{array}{l}\text { Statistically significant at P }<0.05 \text {. } \\
\text { Group I: Subjects with exposure duration 1-10 years; Group II: Subjects with exposure duration of } 11-20 \text { years; }\end{array}$ & \\
$\quad$ Group III: subjects with exposure duration $>20$ years.
\end{tabular}

Table 3: Plasma levels of GGT, Copper, uric acid, Bilirubin and Globulin.

\begin{tabular}{lcccccc}
\hline Group & \multicolumn{1}{c}{$\begin{array}{c}\text { I } \\
(\mathbf{n}=\mathbf{2 5})\end{array}$} & $\begin{array}{c}\text { II } \\
(\mathbf{n = 2 4 )}\end{array}$ & $\begin{array}{c}\text { III } \\
(\mathbf{n = 1 7})\end{array}$ & $\begin{array}{c}\text { Controls } \\
(\mathbf{n}=\mathbf{2 7})\end{array}$ & $\mathbf{F}$ & $\mathbf{P}$ \\
\hline GGT $(\mathrm{U} / \mathrm{L})$ & $20.57^{\mathrm{C}} \pm 1.54$ & $34.46^{\mathrm{B}} \pm 3.05$ & $54.92^{\mathrm{A}} \pm 18.30$ & $28.52 \pm 1.91$ & 3.76 & $<0.05$ \\
$\begin{array}{l}\text { Copper } \\
(\mu \mathrm{mol} / \mathrm{L})\end{array}$ & $15.10 \pm 0.50$ & $15.40 \pm 0.80$ & $17.10 \pm 2.70$ & $14.30 \pm 0.40$ & 0.932 & $>0.05$ \\
$\begin{array}{l}\text { Uric acid } \\
(\mu \mathrm{mol} / \mathrm{L})\end{array}$ & $311.78^{\mathrm{C}} \pm 7.74$ & $326.66^{\mathrm{C}} \pm 11.34$ & $355.22^{\mathrm{C}} \pm 13.69$ & & 3.78 & $<0.03$ \\
$\begin{array}{l}\text { Conj. } \\
\begin{array}{l}\text { Bilirubin } \\
(\mu \mathrm{mol} / \mathrm{L})\end{array}\end{array}$ & $2.30 \pm 030.17$ & $2.28 \pm 30.24$ & $2.76 \pm 030.36$ & $2.10 \pm 30.24$ & 1.13 & $>0.05^{\prime}$ \\
\hline
\end{tabular}

A, B, C: Statistically significant at $\mathrm{P}<0.05$.

Group I: Subjects with exposure duration 1-10 years; Group II: Subjects with exposure duration of 11-20 years;

Group III: subjects with exposure duration $>20$ years. 
Table 4: Correlation between exposure duration to occupational chemical mixtures and GGT, $\mathrm{Cu}$, Urate, Conjulated bilirubin and Globulin.

\section{Exposure Group n=66}

\begin{tabular}{llc}
\hline & \multicolumn{2}{l}{ Exposure duration } \\
\cline { 2 - 3 } & $\mathrm{r}$ & $\mathrm{p}$ \\
GGT & 0.30 & $<0.05^{*}$ \\
Copper & 0.18 & $>0.05$ \\
Uric acid & 0.34 & $<0.01^{* *}$ \\
Conj. Bilirubin & 0.17 & $>0.05$ \\
Globulin & 0.04 & $>0.05$ \\
\hline
\end{tabular}

** Correlation is significant at $\mathrm{P}<0.01$.

* Correlation is significant at $\mathrm{P}<0.05$.

Table 5: Correlation of GGT, Urate conjugated bilirubin and total globulin.

\section{Exposed Group (n-66)}

\begin{tabular}{|c|c|c|c|c|}
\hline & \multicolumn{2}{|c|}{ Uric acid } & \multicolumn{2}{|c|}{ Copper } \\
\hline & $\mathbf{r}$ & $\mathbf{p}$ & $\mathbf{r}$ & $\mathbf{p}$ \\
\hline GGT & 0.27 & $<0.05^{*}$ & 0.01 & $>0.05$ \\
\hline Conjugated bilirubin & -0.06 & $>0.05$ & -0.03 & $>0.05$ \\
\hline Total Globulin & 0.22 & $>0.05$ & 0.22 & $>0.05$ \\
\hline
\end{tabular}

\section{DISCUSSION}

In the developing and restructuring nations, mixed chemical exposure has become a public health issue (Yáñez et al., 2002). There is therefore a great need for developing a comprehensive health risk assessment system (including easily affordable biomarkers) useful to both public health personnel and environmental managers for an effective management of the health hazards associated with the increasing chemical exposure, with a special emphasis on mixed chemical toxicity and its role in mutagenesis and chemical carcinogenesis. The usefulness of such biomarkers in the Nigerian setting has been previously highlighted (Babalola et al., 2009).
A growing body of knowledge indicates that oxidative stress, xenobiotics detoxification and angiogenesis contribute to the development of genomic instability and uncontrolled proliferation (Reuter et al., 2010; Klaunig et al., 2010). Gamma-glutamyl transpeptidase though an important member of the biologic detoxification system, like GST-P is poorly recognized, thus its evaluation as a potential biomarker along with uric acid, copper and the other parameters for the assessment of exposure to potentially deleterious chemicals and associated preneoplastic events appears desirable.

The trend of increasing GGT levels with increasing duration of exposure observed in the present study is most probably a response to exposure to chemicals and not hepatic 
dysfunction as other tests of hepatic function were similar between tests and controls.

Substantial evidence now supports the view that induction of phase II enzymes (such as GGT) is a critical and sufficient mechanism for cellular protection against the toxic and carcinogenic actions of reactive intermediates, particularly in the liver (Alkozai et al., 2014) and generally at the cellular levels of tissues (Ayila et al., 2003). Secondly serum GGT levels even within normal reference range have recently been proposed as an early and sensitive marker of oxidative stress based on both experimental and epidemiological observations (Lee et al., 2004). Thus the slight non-significant increase in GGT level is biologically significant. Consequently in addition to the possible roles of GGT as a biomarker of detoxification and oxidative mutagenesis, this report also appears to suggest a likely scientific basis (mechanism) for the possible usefulness of GGT for early detection of chemical toxicity and preneoplastic events.

It has been demonstrated that oxidative mutagenesis by the GGT system in that GGT-rich tumors grow three times faster than GGT-poor tumors and membrane gamma-glutamyl transferase activity has been reported to promote iron-dependent oxidative DNA damage in melanoma cells (Corti et al., 2009). Thus serving as bio-indicator, this observation appears to corroborate the demonstration by these investigators that GGT is induced to high levels in the very early stages of liver and skin cancers. Therefore, the elevated GGT levels in the chemically exposed subjects in general and the significantly elevated GGT activity in group III subjects (severe exposure group; exposure duration $>20$ years) greater than group I (subjects with exposure duration 1-10 years) and controls (zero exposure duration) respectively in this report may be considered an adaptive response which allows GGT-rich cells to survive toxic assaults or environment and consequently serving as a biomarker.

Glutathione -S-transferase P, a closely related enzyme to GGT, is a well-established marker protein for cancer diagnosis as it is expressed abundantly in tumor cells (Aliya, 2003). The most important phase II detoxification pathway is Glutathione -Stransferases (GSTs) catalyzed conjugation of GSH to the electrophilic center of various carcinogens and mutagens (Aliya, 2003), thereby depleting glutathione. Therefore, the observation of raised GGT activities which were significantly different across the groups in this study may be a compensatory mechanism (up-regulation) for the replenishment of GSH concentration within the cells.

Furthermore, the participation of GGT in the generation of intracellular glutathione may enhance cellular resistance to chemical toxicity and selective growth advantages to pre-neoplastic cells. This appears to be in agreement with the findings of Corti et al. (2010) and Singh et al. (2011) that GGT provides pre-neoplastic cells with resistance to acute toxicity of carcinogens owing to its participation in phase-II detoxification of xenobiotics. Several lines of evidence indicate that the advantage may be provided by the ability of GGT to retrieve GSH constituents, which leads to increased cellular GSH or replenishment of GSH (Borud et al., 2000; Mikkelsen et al., 2002). The study of Lee et al. (2004) has shown that cellular GGT catalyses the first step in degradation of extracellular glutathione. Once in the extracellular environment, there is minimal cellular uptake of intact glutathione. Rather, GSH is metabolized by GGT which removes the gamma-glutamyl group from GSH, after which cysteinylglycine can be cleaved by a membrane dipeptidase. The released cysteine can be transported into the cell and used as a substrate for the de novo synthesis of GSH, a very potent intracellular antioxidant. Therefore, the gamma-glutamyl cycle involving GGT is generally thought to be the major pathway by which cells utilize extracellular GSH for the de novo synthesis of intracellular GSH (Lee et al., 2004). The increase in GGT activity with exposure duration across the groups may be related to a proportional degree of induction of GGT, which is an important response to chemical 
stress via the detoxification of xenobiotics. Thus with increasing chemical burden which is cumulative, there is an associated increased GGT induction.

The significantly elevated uric acid level in the chemical cohort compared to controls seems to corroborate the elevation in GGT as a response to toxic challenge. Uric acid is an endogenous antioxidant and its elevation may indicate an ongoing repair to DNA damage (Olinsk et al., 2007; Settle and Klandorf, 2014). Indeed, uric acid has been inversely correlated to 8-hydroxyl deoxyguanosine (8-OHdG), a marker of DNA damage (Yoshida, 2002; Dziamin, 2007). The significant positive correlation $(\mathrm{r}=0.27$, $\mathrm{p}<0.05$ ) between uric acid and GGT in the exposed group, supports earlier hypothesis that GGT may in part be a marker of oxidative stress. It has been demonstrated that primary human memory $\mathrm{T}$ cells expressed higher level of GGT than native $\mathrm{T}$ cells (Borud et al., 2000; Mikkelsen et al., 2002). This observation suggests that increased GGT expression may provide an adaptive advantage in permitting these cells to resist oxidative stress. Furthermore, several studies have shown that the expression of GGT on other cell types might be involved in the facilitation of cellular proliferation under conditions of limited extracellular cysteine or depletion of intracellular GSH (Mikkelsen et al., 2002; Singh et al., 2011).

Thus, up-regulation of GGT which was positively correlated with uric acid in this report may play a role in protecting cells from oxidative stress or thiol depletion by enhancing the maintenance of intracellular GSH. On the other hand, since oxidative stress plays a central role in chemical carcinogenesis, the finding of significant positive correlation of uric acid with GGT in the present study may suggest a strong association between plasma GGT and cancer risk in occupational chemical exposure. This may result from the fact that GGT-induced oxidative damage may "initiate" preneoplastic cells to undergo further genetic alterations that are required to attain autonomy. This appears consistent with the findings of Corti et al. (2010) and Singh et al. (2011) who associated elevated GGT activity in pre-neoplastic cells with the formation of reactive oxygen radicals, tumour progression and mutagenesis.

No previous reports exist on the evaluation of GGT as a biomarker of oxidative stress or detoxification or as a marker of pre-neoplastic lesion in occupationally exposed participants. However, Aziza et al. (2004) in their study on the effect of environmental pollution on the health of some fishermen observed that they (fishermen) showed elevated GST activity accompanied by low GSH content. They also observed a significant elevation in GGT activities. These findings appear to be consistent with those reported here in spite of the differences in study population. Oxidative DNA damage is an important contributing factor to the carcinogenic process (Reuter et al., 2010; Klaunig et al., 2010). The elevated uric acid levels across the exposure categories may represent an antioxidant-adaptive response to combat oxidative stress induced by mixed chemical toxicity. This response may also play a role in the DNA repair mechanism for possible oxidative DNA damage associated with chemical exposure. It is probably important to note that uric acid is one of the most abundant antioxidants in plasma (Klaunig et al., 2010). Additionally, the stabilization of ascorbate as an antioxidant appears to be dependent on urate action and ascorbic acid can regenerate other antioxidants such as $\alpha$-tocopheroxylurate and $\beta$-carotene (Naidu, 2003). Urate not only behaves as a radical scavenger but also stabilizes ascorbate in biological fluids. This stabilizing effect appears to be due to an inhibition of iron-catalyzed oxidation of ascorbate. Ascorbate stabilization is particularly evident in human serum and is largely due to iron chelation by urate. Unlike radical-scavenging reactions, this protective effect of urate is not associated with its depletion because a stable, non-catalytic urate-iron complex is formed. Urate not only substitutes as a biological reductant and antioxidant but spare ascorbate by 
mechanisms other than competitive radical scavenging and radical repair (Naidu, 2003; Sautin and Johnson, 2008).

The strong association of uric acid with exposure duration (a reflection of chemical burden) may indicate the severity of the oxidative stress as well as suggestive of oxidative stress being involved in the pathogenesis of mixed chemical toxicity even in mild environmental exposure to chemical mixture. This appears to make uric acid a potential biomarker of these events and their consequences. This observation therefore appears to support the hypothesis that uric acid is a potent antioxidant that might protect against cancer (Ames et al., 1981) and subsequent supported by more recent studies of the relationship between uric acid and cancer risk (Ghaemi-Oskouie and Shi, 2011; Fini, 2012; Kang and Ha, 2014; Yan et al., 2015). Therefore, the significant positive correlation between duration of exposure and uric acid concentration in the exposed group may be an indirect reflection of and/or a corroboration of the strength of association between chemical exposure and risk of cancer. However, some recent reports (Fini, 2012; Kang and Ha, 2014; Yan et al., 2015) are not in agreement with the hypothesis that uric acid might offer protection against occurrence and indirectly as a marker of pre-neoplastic events. The reason for this divergence is unclear, indicating need for more studies. However several studies have consistently demonstrated that elevated uric acid levels in lead toxicity; a subset of mixed chemical exposure may serve as a reliable index of environmental toxic assault (Anetor and Adeniyi, 2001).

Although the mean $\mathrm{Cu}$ level in the exposed group was not significantly different from the unexposed group, it was raised in the exposed group. This is probably a subtle response to free radical burden as a consequence of chemical exposure. Studies have previously shown the association between copper excess and tumour angiogenesis (Nasuewicz et al., 2002; Mir et al., 2007; Swaminathan et al., 2011). The non- significant increase in $\mathrm{Cu}$ level may be as a result of adequately protective effect of urate.

Anetor and Adeniyi (2001) found significantly elevated $\mathrm{Cu}$ level in individuals occupationally exposed to lead. The elevation was attributed to the antioxidant property of copper containing proteins. The nonsignificant correlation between copper and uric acid is not easily explained, it may imply that they operate independently.

The non-significant observation in total globulins corroborates that of $\mathrm{Cu}$ (component of the acute phase reactant globulin) and may indicate similar immunological status. The association of raised globulin levels with inflammation (O'Connell et al., 2005) may probably suggest the existence of inflammation in the population they investigated. Interestingly however, total globulin was positively correlated with uric acid and copper probably suggesting mild inflammatory response to chemical exposure. Lee et al. (2004) have shown that GGT levels in serum predicted fibrinogen and C-reactive protein levels, which are markers of inflammation or acute phase response.

Taken together, the findings in this report suggest that GGT, even within its routine reference interval may be a biomarker reflecting the extent of exposure to xenobiotics. Thus plasma GGT level may be a reliable marker of chemical toxicity and preneoplastic activities. These findings also appear to provide insights into GGT induction as a possible reliable inexpensive biomarker of genomic instability in populations at high risk of mixed chemical toxicity with associated carcinogenic process. Especially when combined with increase and correlation with urate. As a mitigation strategy, micronutrients intake as well as some phytochemicals may provide some protection and ameliorate susceptibility to this mixed chemical exposure (Adejuwon et al., 2014; Anetor, 2016).

We must continue in our scientific search and public health efforts to identify potential carcinogenic hazards to humans using biomarkers, and should no longer permit unregulated exposure to those agents 
considered carcinogenic or probably carcinogenic. The present study indicates that GGT in combination with uric acid may be a very useful marker or tool in all these efforts to identify or prevent carcinogenic events, particularly in resource poor industrializing countries.

\section{Conclusion}

The data from this study establishes the existence of oxidative stress in exposed participants that may lead to mutation and risk of cancer. GGT, like GST-P may be an inexpensive marker of chemical toxicity embracing genotoxicity and pre-neoplastic events. Association of serum GGT and urate in chemical exposure may be of great public health significance in developing countries as an early inexpensive biomarker of genomic instability particularly after prolonged exposure.

\section{COMPETING INTERESTS}

The authors declare that they have no competing interests.

\section{AUTHORS' CONTRIBUTIONS}

All authors have contributed significantly to the research design, laboratory analysis and in the preparation of the manuscript for publication.

\section{ACKNOWLEDGMENTS}

The authors wish to acknowledge all participants for granting informed consent to be enrolled into the study, and all others that gave technical assistance in the course of the study.

\section{REFERENCES}

Yáñez L, Ortiz D, Calderon J, Diaz-Barriga F. 2002. Overview of human health and chemical mixtures: problems facing developing countries. Environmental Health Perspectives, 110(6): 901-909.

Gashaw A, Teshita A and Getachew T. 2016. Environmental tobacco smoke exposure and its health impacts: a review. Int. J. Biol. Chem. Sci., 10(3): 1370-1381.
Reuter S, Gupta SC, Chaturvedi MM, Aggarwal BB. 2010. Oxidative stress, inflammation, and cancer: How are they linked? Free Radic Biol Med., 49(11): 1603-1616. Doi: 10.1016/j

Klaunig JE, Kamendulis LM, Hocevar BA. 2010. Oxidative Stress and Oxidative Damage in Carcinogenesis. Toxicol Pathol., 38: 96-109. DOI: 10.1177/0192623309356453

de Martel C, Ferlay J, Franceschi S, Bray F, Vignat J. 2012. Global burden of cancers attributable to infections in 2008: a review and synthetic analysis. The Lancet Oncology, 13: 607-615.

Whitfield JB. 2007. Serun gammaglutamyltransferase and risk of disease. Clin. Chem., 53: 1-2.

Lee DH, Blomloft R, Jacobs DR. 2004. Is Serum gammaglutamyl transferase a marker of oxidative stress? Free Radic. Res., 38: 335-539.

Satoh K, Hatayama I. 2002. Anomalous elevation of glutathione S-transferase Pform (GST-P) in the elementary process of epigenetic initiation of chemical hepatocarcinogenesis in rats. Carcinogenesis, 23(7):1193-1198.

Radovanovic S, Savic-Radojevic A, Pekmezovic T, Markovic O, Memon L, Jelic S, Simic D, Radic T, PljesaErcegovac M, Simic T. 2014. Uric Acid and Gamma-glutamyl Transferase Activity Are Associated With Left Ventricular Remodeling Indices in Patients With Chronic Heart Failure. Rev Esp Cardiol., 67(08): 632-642. DOI: 10.1016/j.rec.2013.11.017

Rahman I, MacNee W. 2000. Oxidative stress regulation of glutathione in lung inflammation. Eur Respir J., 16: 534-554.

Bergmeyer HU, Hørder M, Rej R. 1986b. International Federation of Clinical Chemistry (IFCC) Scientific Committee, Analytical Section: approved recommendation (1985) on IFCC methods for the measurement of catalytic concentration of enzymes. J. Clin. Chem. Clin. Biochem., 24: 481-495. 
Tietz NW, Shuey DF. 1986. Reference intervals for alkaline phosphatase activity determined by the IFCC and AACC reference methods. Clin. Chem., 32: 15931594.

Committee of Enzymes of the Scandinavian Society for clinical chemistry and clinical physiology 1976. Recommended method for the determination of $\gamma$-glutamyl transferase in blood. Scand J Clin Lab Invest., 36:119-125.

Town MH, Gehm S, Hammer B, Ziegenhorn J. 1985. Enzymatic in vitro test for the quantitative determination of uric acid in human serum. J Clin Chem Clin Biochem., 23: 591 .

Osheim DC. 1983. Atomic absorption determination of copper: a collaboratory study. J. Assoc of Anal Chem., 66: 11401142.

Doumas BT, Bayse D, Carter RJ, Peters T, Schaffer R. 1981. A candidate reference method for determination of total protein in serum: Development and validation. Clin. Chem., 27: 1642.

Jendrassik L, Groff P. 1938 Simplified photometric method for determination of blood bilirubin. Biochemical J., 297: 8189.

Babalola OO, Anetor JI, Adeniyi FAA. 2009. Biochemical markers of liver and kidney functions in Nigerian hypertensive patients. Int. J. Biol. Chem. Sci., 3(2): 304-309.

Alkozai ED, Lisman T, Porte RJ, Nijstena MW. 2014. Early elevated serum gamma glutamyl transpeptidase after liver transplantation is associated with better survival. F1000Res., 3: 85.

Ayila S, Redanna P, Thyagaraju K. 2003. Does glutathione S-tranferase P, (GST-Pi) act as marker protein for cancer? Mol. Cell Biochem., 253: 319-327.

Corti A, Duarte TL, Giommarelli, C, De Tata V, Paolicchi A, Jones, GDD, Pompella A. 2009. Membrane gamma-glutamyl transferase activity promotes irondependent oxidative DNA damage in melanoma cells. Mutation Research, 669: 112-121.
Singh A, Bhat TK, Sharma OP. 2011. Clinical Biochemistry of Hepatotoxicity. J Clinic Toxicol, S4: 001. Doi:10.4172/21610495.S4-001

Borud O, Mortensen B, Mikkelsen IM, Leroy P, Wellman M, Huseby NE. 2000. Regulation of gamma-glutamyltransferase in cisplatin-resistant and -sensitive colon carcinoma cells after acute cisplatin and oxidative stress exposures. Int $J$ Cancer, 88: 464-468.

Mikkelsen IM, Huseby NE, Visvikis A, Moens U. 2002. Activation of the gammaglutamyltransferase promoter 2 in the rat colon carcinoma cell line CC531 by histone deacetylase inhibitors is mediated through the Sp1-binding motif. Biochem Pharmacol, 64: 307-315.

Olinski R, Siomek A, Rozalski R, Gackowski D, Foksinski M, Guz J, Dziaman T, Szpila A, Tudek B. 2007. Oxidative damage to DNA and antioxidant status in aging and age-related diseases. Acta Biochimica Polonica 54 (1) 11-26

Settle T, Klandorf H. 2014. The Role of Uric Acid as an Antioxidant in Neurodegenerative Disease Pathogenesis. Brain Disord Ther, 3: 129. Doi:10.4172/2168-975X.1000129

Dziaman T, Gackowski D, Rozalski R, Siomek A, Szulczynski J, Zabielski R, Olinski R. 2007. Urinary excretion rates of 8-oxoGua and 8-oxodG and antioxidant vitamin levels as a measure of oxidative stress in healthy, full-term newborns. Free Radic Res., 41: 997-1004. Doi: 10.1080/10715760701468757

Naidu KA. 2003. Vitamin C in human health and disease is still a mystery? An overview. Nutrition Journal, 2: 7. DOI: 10.1186/1475-2891-2-7

Sautin YY, Johnson RJ. 2008. Uric acid: The Oxidant-Antioxidant. Paradox. Nucleosides Nucleotides Nucleic Acids. 27(6): 608-619. Doi:10.1080/15257770802138558.

Ames BN, Cathcart R, Schwiers SE, Hochstein PC. 1981. Uric acid provides an antioxidant defense in humans against oxidant and radical caused ageing and 
cancer: A Hypothesis: Proc. Natl. Acad. Sci., 78: 6858-6862.

Ghaemi-Oskouie F, Shi Y. 2011. The role of uric acid as an endogenous danger signal in immunity and inflammation. Curr Rheumatol Rep., 13(2): 160-166. Doi: 10.1007/s11926-011-0162-1

Fini MA, Elias A, Johnson RJ, Wright RM. 2012 Contribution of uric acid to cancer risk, recurrence, and mortality. Clin Transl Med., 1: 16. Doi: 10.1186/2001-1326-116

Kang DH, Ha SK. 2014. Uric acid puzzle: dual role as antioxidant and pro-oxidant. Electrolyte and Blood Pressure, 12(1): 16.

Yan S, Zhang P, Xu W, Liu Y, Wang B, Jiang T, Hua C, Wang X, Xu D, Sun B. 2015. Serum uric acid increases risk of cancer incidence and mortality: a systematic review and meta-analysis. Mediators Inflamm, 4(76): 42-50.

Anetor JI, Adeniyi FAA. 2001. Antioxidant status in occupational lead Toxicity in Nigeria. Biokemistri, 11: 1-7.

Nasulewicz A, Wietrzyk J, Opolski A. 2002. The role of copper in tumor angiogenesis Cell. Mol. Biol. Lett., (7) supplement: 5-8.
Mir MM, Dar NA, Salam I, Malik MA, Lone MM, Yatoo GN, Ahmad A, Shah A. 2007. Studies on Association Between Copper Excess, Zinc Deficiency and TP53 Mutations in Esophageal Squamous Cell Carcinoma From Kashmir Valley, India-A High Risk Area. Int $J$ Health Sci., 1(1): 35-4.

Swaminathan S, Gangadaran P, Venkatesh T, Ghosh M. 2011. Association between serum copper and tumor markers CEA and CA 125. Journal of Pharmaceutical and Biomedical Sciences, 9(9): 15.

O'connell TX, Timothy JH, Barsam K. 2005 Understanding and Interpreting Serum Protein Electrophoresis. Am Fam Physician., 71(1): 105-112.

Adejuwon SA, Imosemi IO, Ebokawe PA, Omirinde JO, Adenipekun AA. 2014. Protecrive role of Telfairia occidentalis in irradiation-induced oxidative stress in rat brain. Int. J. Biol. Chem. Sci., 8(3): 843853.

Anetor GO. 2016. Awareness of healthcare professionals on micronutrients use in disease prevention and physical activity in Ibadan, Nigeria. Int. J. Biol. Chem. Sci., 10(2): 642-651. 